\title{
DYNAMICS OF TEACHING SCIENCE EDUCATION IN A CHANGING ENVIRONMENT
}

\author{
Jacinta A. Opara \\ Center for Environmental Education, Universidad Azteca \\ Chalco-Mexico \\ E-mail address: nkasiobisilasoguzor@yahoo.com
}

Keywords: dynamics; teaching; science education; changing environment

\begin{abstract}
During the past few decades, resources have been allocated in many parts of the world for developing curricula in school science, which were directed to the need for more scientists that can promote national development. In the light of this, many developing country has emphasized the education of its citizens in Science, Technology and Mathematics (STM). This mode was reflected in the Nigerian National Policy on Education when it recommended an enrolment ratio of 60:40 in favour of STM and related courses in higher institution of learning (Federal Republic of Nigeria 2004). This guideline became necessary in order to boost our manpower development and researches in these professions. The role of STM in the development of a nation cannot be over emphasized as it is very important in solving a country's problem.STM is the base for the overall development of a nation, the instrument for the orderly and ethical behaviour of it citizens.
\end{abstract}

\section{INTRODUCTION}

The concept 'Science Education' is a twin word. To understand it better, each of the words (concepts) will be defined separately, and then it can be defined as a single concept.

For the purpose here, we shall define the concepts as a course or discipline. Therefore, the following questions can be asked

(1) What is teaching

(2) What is science

(3) What is integrated science

(4) What is science education

\section{WHAT IS TEACHING}

Here, we shall define teaching as:

an environmental arrangement which inevitably involves an organism mentally and/or physically in a set of organised activities, and facilities those activities in consonance with its goal or lack of goals, its age (mental and /or chronological) and its capacity in an attempt to further its covert and overt behaviours. The result of these activities are determined by the increment in the rate of responding of existing behaviours, a re-arrangement of existing behaviours or any combination of these.

However, before we go on with this definition, let us briefly discus the concept 'learning'. This is because

(1)teaching and learning go together

(2)a teacher should know the process of learning and what is all about

(3)the knowledge is essential for effective and efficient teaching process

Learning is seen as a process through which behaviour is initiated, modified or changed 


\section{The Learning Process}

Objects, events, problems etc. learning. learned behaviour input perception process(activities) output stage 1 stage 2 stage 3

The illustration shows 'input' as the first stage in learning. This could be in form of objects, events problems etc. The input is taken in form of perception through sensory organs. This input and perception results to covert and overt activities. The covert activities are those activities such as thinking, feeling imaging etc. This describes the lower level of learning which cannot be observed directly. While the overt activities are higher level of learning that could be seen directly such as writing, drawing etc. The result or end product of these activities are what is refered to as learned behaviours. These behaviours are what is known as the output of the learning process.

However, learning comes in a triangular form involving the learner, activities and goal.

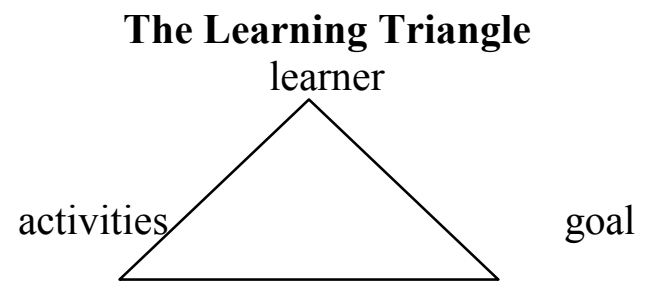

Learning occurs when a goal is set and pursued in a formal classroom. At times, learning only involves the learner(organism) and activities. This is known as incidental or accidental learning, whereby the learner come in contact with an object, event, or problem without prior intention or established goal. In many cases, it is common in informal state.

From the above description, there are both formal and informal learning. The informal involves the learner and his activities while the formal involves the learner, his activities and the goal which is set and pursued in a formal classroom. At this point, comes the focus of teaching by the teacher to achieve the set goal.

\section{The Teacher}

The teacher facilitates the process of learning, in formal education. He teaches the learner. Obviously, he plays the following roles

(1)know the subject matter

(2)the methods and strategies of teaching the learner

(3)the method of getting to know the learner 


\section{Teachers Roles}

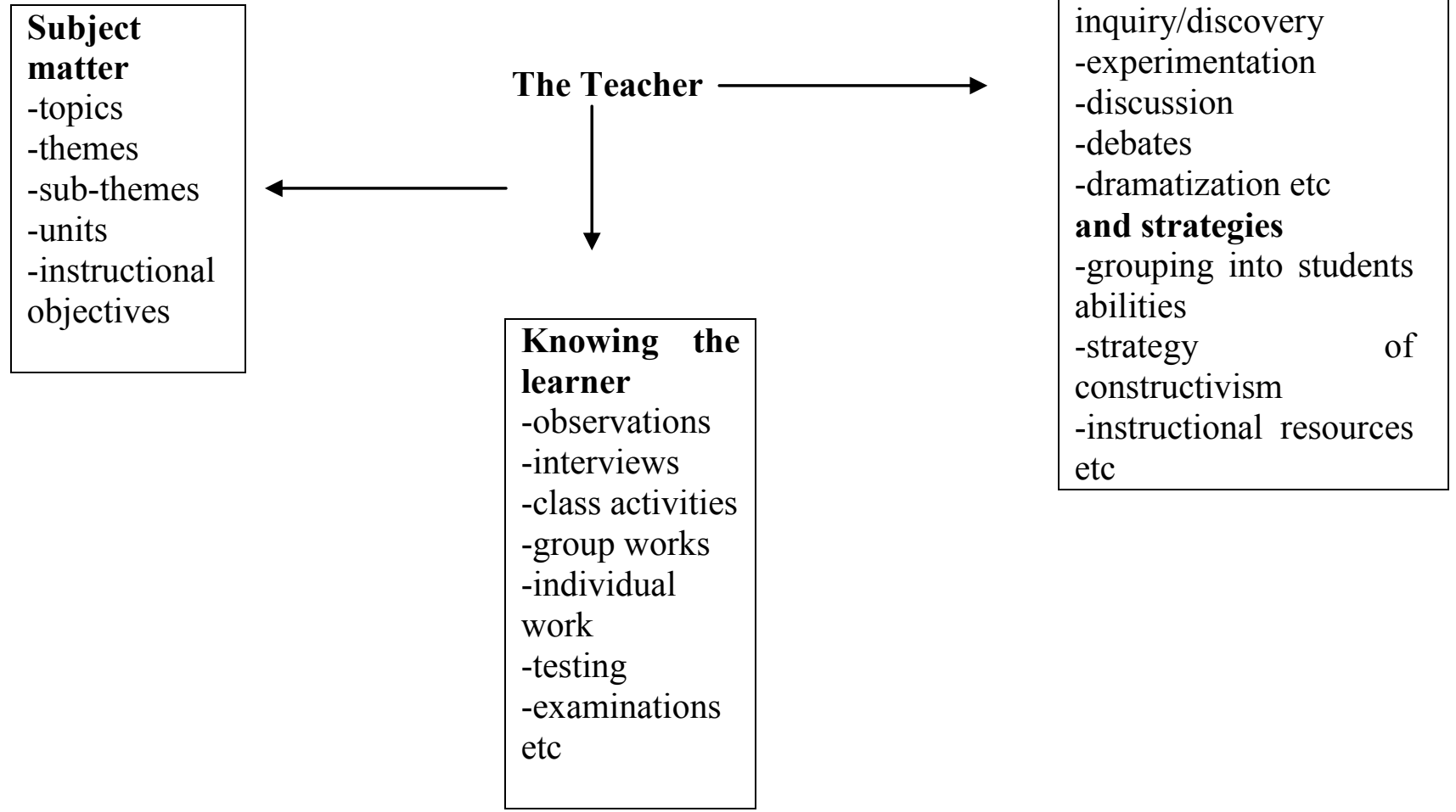

The teacher plays these roles to bring an effective and efficient teaching and learning process. In this, teaching is an art as well as science. Science describes, explains and imitates nature and that part of teaching which is scientific and serves its purpose better if it imitates nature.

\section{WHAT IS SCIENCE}

The word 'Science' invariably makes us think of big textbooks, laboratory/equipment, white laboratory coat, microscopes, equations etc. Though these are aspects of science but it is not all about science. Science is part of our everyday life, where it exists all around us. Science has many disciplines such as chemistry, physics, biology, mathematics, engineering etc

Some of the definitions of science include;

(1) A search for new and more accurate knowledge about the earth

(2) An intellectual activity through which man seeks to understand nature

(3) Activities culminating into testable, falsifiable and verifiable body of knowledge

(4) A knowledge of the physical and biological principles that underlie our lives

(5) An attempt by human beings to organise their experiences about nature into a meaningful system of explanation

All the above definitions tend to agree on a common fact that is presenting science as a venture through which knowledge is sought and gained. In other words, to gain a particular knowledge of the universe, an activity or series of activities have to be carried out. With the knowledge we have gained from the activities, we can explain a particular event.

Man as the highest of all the animals "HOMOSAPIEMS" always want to know things about his environments, this he carries out activities which is the essence of the science.

From the above, two things can be derived, science is viewed as a product as well as process. The product aspect of science presents science as a body of knowledge already acquired and is presented as facts, principles, laws, theories etc .The process aspect of science presents it as a method of inquiry into nature of life (activities). The processes of science therefore include: observation, recording, counting, drawing, experimentation, formulation of hypotheses, inferences, conclusion etc. One engaged in carrying out any of the above activities is in a way doing science. 
It should be noted that science is not just the single subject people offer as biology, chemistry, physics, mathematics or engineering. These are referred to as branches of science. These branches in turn are linked to each other like the integrated nature of science which cut across all the natural sciences thus presenting science as one whole and not fragments. This creates an integrated functional association between sciences. To state what science is, let us see the diagram below.

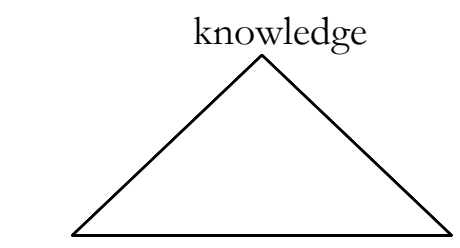

attitude skill

\section{Science}

The word "Science" may be defined as rationally structured knowledge about nature which embraces systematic methods and positive attitudes for its acquisitions, teaching, learning and application. Science is composed of attitude, skill and knowledge (ASK) each of which has different domains involved. For example, knowledge involves cognitive domain and skill involves cognitive and psychomotor domains. This is because science in skill involves critical thinking in attributing (cognitive domain). We also have manipulative skill that uses psychomotor domain. While attitude such as accuracy, involves affective domain. Each of these domains is catered for in the process of education.

\section{WHAT IS EDUCATION}

Education is seen as a process which includes all the ways in which a person deliberately tries to influence the behaviour of another person. This behaviour may include knowledge, skills, habits, values and attitudes. Education is of two kinds, formal and informal education. Formal education is organised while informal education is not organised.

From explanation above, science and education work hand in hand to produce the learner(an individual) as educated. That is when he has gained and applied all the principles underlying the concept

\section{WHAT IS SCIENCE EDUCATION}

This is defined as the study of interrelationship between science as a discipline and the application of educational principles to its understanding, teaching and learning. Science education can also be defined as a discipline or field of study concerned with the integration of science content and processes with pedagogy in order to promote meaningful understanding and application of science among learners, or the study of science content and process with emphasis on how best to promote their teaching and learning in order to achieve optimum benefits.

\section{ROLES OF SCIENCE EDUCATION}

Science Education having been recognised worldwide as the bedrock of scientific and technological accomplishments and development, science educators therefore have been increasingly concerned with ways of improving the quality of teaching and learning of science in schools for a greater height as;

1. To give an essential background of knowledge for cultural development. It expands the individual's knowledge of the universe and of his position in it. It helps in the appreciation and enjoyment of nature and life.

2. It gives many opportunities to foster the scientific method and discipline, since it trains students to observe and think clearly and carefully. This training should whenever possible 
be applied to real and worthwhile problems affecting the personal life and thought of the individuals so that such benefits may be transferred to his other activities.

3. It stresses the need to appreciate the meaning of scientific life, spirit and endeavour, openmindless, intellectual honesty, self sacrifice and devotion which ought to serve as ideas to future citizen.

4. Science acquaints the individual with knowledge of chemical facts needed not only for many trades and professions, but also by all citizens, to enable them to live happily, wellbalanced and useful lives. Future citizens ought also to know of possible influence of new chemical discoveries and should realise need for proper control. It is therefore necessary to understand, as a minimum the simpler words and definitions in science, the relationship between science and other fields of knowledge and the elementary facts and principles of this subject, so that in later life the individual may keep himself informed of important developments.

Like a barometer, the scientific and technological capability of a nation has easily become the social index and determining factor for assessing the economic progress, prosperity and power of nations.

\section{A MODEL FOR QUALITY TEACHING OF SCIENCE}

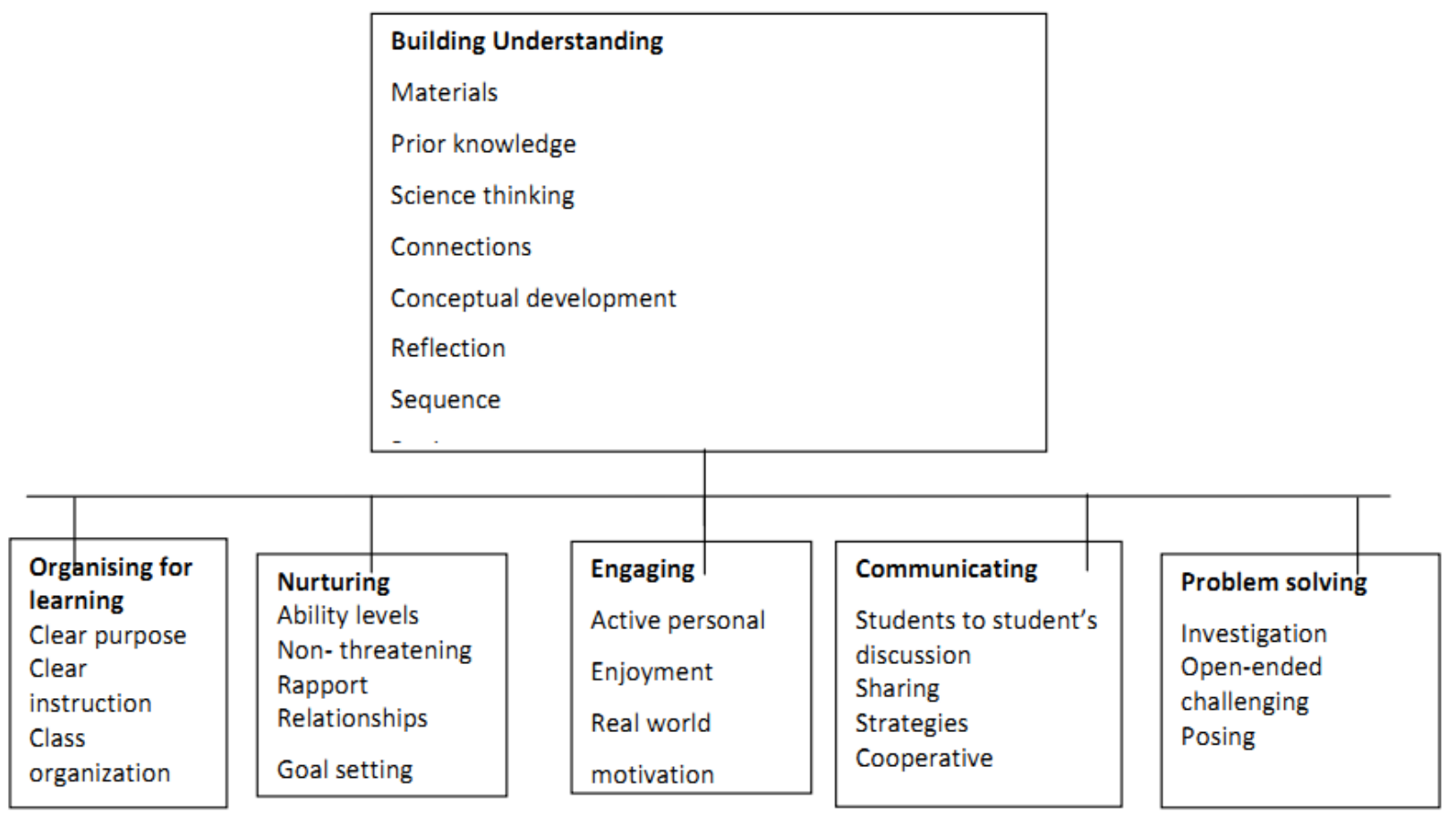

Source: Sullivan and Monsley (1994)

Based on the diagram, there are some relationships that exist between the six components of quality teaching in sciences. For instance, Building understanding facilitates the other components; organising for learning, nurturing, engaging, communicating and problem solving.

The methods of teaching adopted by teachers influence the students learning style and the acquisition of science skills which is greatly needed for science and technological accomplishments in Nigeria. In addition, this is the activity based teaching methods that involves the learner in the teaching- learning process. Some of the activity based on teaching methods advocated by scientists as a result of research findings and these includes discovery, problem-solving, cooperative learning, excursion/field trips. Others include teaching method, like concept mapping, demonstration, laboratory investigation and problem-solving methods among others. 
Obviously, as awareness in science and technology increases, science education curriculum and methodology also increases to follow upcoming trends by associating the curriculum with the environment and society.

\section{IMPROVING THE QUALITY OF SCIENCE TEACHING THROUGH INTERDISCIPLINARY APPROACH}

There is more to science education than simply learning about theories and laws. It also includes learning how to initiate a functional integrative association between science curriculum and other curriculums arising at providing individuals with a solid technological background to gain knowledge, skills and attitudes required in a rapidly changing world.

Firstly, the concept of interdisciplinary science is one of the important disciplines that concentrate on teaching science courses alongside with other courses such as social Studies and linguistic studies (Glatthom and Jailhall, 2000). In developing science methodology, it is expected that science curriculums will be more associated and integrated with other curriculums such as technology, mathematics, social science, environmental science, health education and others.

Secondly, the innovative approaches for implementing interdisciplinary science in science methodology are very rewarding. Enhancement in this approaches are as follows:

1. Integrated Science Approach: Based on the development in society and advancement in social, economical, political and cultural life brings the integrated science approach as a new trend in the field of science. Many studies approve the effectiveness of the integrated approach which reacts to the traditional approaches that aims to deal with the topic as an integrated coordinated unit, away from the dualism and duplication.

2. Environmental approach: This is considered as appropriate for systematizing the interdisciplinary science curriculums. It recognises the place of the child's environment in the child's life and overall wellbeing. Hence, the child's learning is always designed in a way that it can enable him fit into his environment. This should among others: (i) inculcate social norms (ii) the spirit of inquiry and creativity through exploration of nature, the environment, art, music and playing with toys, etc.

3. Citizenship approach: This approach helps citizens to acquire analytical thinking, and problem and understanding of the past as a guide for the appreciation of the present. The science curriculum that attempts to acquaint scientific illumination and civilization, combines between science and technology, society and environment in a dynamic constant relation for a real world.

4. Systematic approach: There is an attitudinal problem with respect to science where students feel that science subjects are too difficult and therefore shy away from it. In this, science concepts must be divided into hierarchical bits in order for the learner to be in control from one bit to another, having a perfect knowledge of the preceding bit. This process enables the learner to move to the next stage of the learning process at his own pace thereby enabling proper understanding. This encourages the teaching of concepts and topics through an integrated system and as such enables the learner to create connections between diverse disciplines.

5. Real life approach: This will acquaint the learners with the understanding of the social problems and issues with regard to their real life in which solutions are proffered to solve these problems. There is need to associate science teaching with reality, and real life state of the learner's concentrations on the social dimension.

6. Science, technology and society approach: Interdisciplinary science curriculum is required to facilitate individual literacy through science, technology and society approach. Translated closely, it is science and technology that is apt to solve the problems of the society brought upon it by nature or itself. Therefore, science and technology are an indispensible component of the society. A bond therefore, exists between science and technology and society which is hard to break. Society is dynamic and grows more and more complex. As the complexity increases, science and technology gets more advanced, but simpler. This 
approach gained more attention from science researchers on the national and international circle as numerous studies are tackled in this field.

7. Futurist approach: This approach could be used to prepare individuals who are capable to keep up with scientific and technological accelerated progress in all fields. It presents modern topics and technological issues that have obvious effects upon individuals and sciences in future. Science education can follow these trends by associating curriculum with the environment and society.

\section{WHY USE INTERDISCIPLINARY APPROACH IN SCIENCE}

Interdisciplinary science in science methodology increases students learning. Helping them to develop knowledge, insights, problem solving skills, self confidence, self efficacy and passion for learning

1. It helps students to uncover preconception or recognize bias. First, by helping students identify insights from a range of disciplines that contribute to an understanding of the issue under consideration. Second, to develop the ability to integrate concepts and ideas from these disciplines into a broader conceptual framework of analysis.

2. Helping students to acquire positive trends and attitude towards the environment which can help them to adjust to the modern world.

3. It helps advance critical thinking and cognitive development. Obtaining a clear understanding of problems with roots in multiple disciplines requires the capacity to integrate ideas and this skills is advanced by interdisciplinary science learning.

4. It helps students appreciate ethical dimensions of concerns. Ethical considerations entail moral concerns which mean accounting for perceptions of right verses wrong, good verses bad, and the provision of justice. Many disciplines steer clear of such subjective phenomena and confine their analysis to more objective factors in an effort to be scientific.

5. It promotes significant learning. Preparing individuals to be capable to keep up with the scientific and technological accelerated progress in all fields.

6. It promotes understanding when students learn in heterogeneous way. Students are heterogeneous in their learning styles and have diverse backgrounds, interest, experiences, talents and values. Drawing in a broad array of frameworks and methodologies will enhance students learning.

7. Helping teachers to apply the topics they have learned which deal with environmental issues and problems related to the real life.

8. Help to prepare individuals who are aware of the scientific and technological civilization, which can help them sustain with the ever increasing national and international science and technology developments. To be able to pursue the present challenges and growth.

9. The world is interdisciplinary. According to The National Council for Teachers of English (NCTE,1995) "educational experiences are more authentic and of greater value to students when the curricula reflects real life, which is multi-faceted rather than being compartmentalized into neat subject-matter packages. In their view, real world problems are complex, so no single discipline can adequately describe and resolve these issues.

\section{RECOMMENDATIONS}

1. There should be regular seminar, conference and workshops to help teachers to improve their teaching skills, get adequate knowledge about modern topics, issues and problems challenging the society and how to solve them in their teaching activities.

2. Nigerian educational planners should include these approaches in the use of interdisciplinary science teaching.

3. Science educators should apply these approaches in interdisciplinary science for science teaching.

4. Government should encourage in-service training programme to get teachers acquainted with recent science teaching methodologies. 
5. In cooperation of the social issues and problems into the course contents for teaching programmes.

6. Science curriculum is expected to follow upcoming trend by associating the curriculum with the environment and society.

7. There should be an emphasis on teacher education programmes to follow the social, cultural, scientific and technological transformations.

\section{CONCLUSION}

The traditional methods of teaching and learning science are no longer adequate to prepare the competent individual who is capable to track the scientific and technological challenges by the modern world. The approaches though discussed differently have relationship between them. Obviously, there is need to create an integrated functional association between science curriculum with other curriculum to train individuals as to cope with the modern world.

Considering the role of science education in the new world of globalization, interdisciplinary science is the best solution to attain these goals.

\section{References}

[1] Amusan, O.O.C. (1992).Hints On the Teaching of Carbon Compounds of the Senior Secondary School Level. Journal of Science Teachers Association of Nigeria, Vol.27, No.2, 98-103.

[2] Gallton, A. And Jaihall (2000). Curriculum for the New Millennium, in Brandt, R.E. (Ed.) Educational in a New Era, U.S.A. Association for Supervision and Curriculum Development, Pp.97-121.

[3] Gobel, D.L., Samuel, K. U, Helgesons, Novak, J. and Butsow, J. (1986). Journal of Research in Science Teaching Vol. 23, No.2, 145-146.

[4] Halah Saeed, B.A and Najah, A.A. (2010). Interdisciplinary Science and Developing Science Teaching. Conference Proceedings. 10th International Educational Technology Conference and Exhibition, Istanbul 26-28 April, Vol.2.

[5] Koleosho, A. (1991). A Strategy for Teaching the Concept of Relative Atomic Mass of an Element. Journal of Science Teachers Association of Nigeria, Vol.27, No.1, 139-142.

[6] Nnadi, E.N. (1991). A Review of Some Uses of Computer Simulations in the Teaching of Physics Concepts at Secondary School Level. Journal of Science Teachers Association of Nigeria, Vol.27, No.X, 175-180.

[7] Nwagbo, C. (1999). Effects of Guided Discovery and Expository Teaching Method on the Attitude towards Biology of Students of Different Levels of Scientific Literacy. Journal of Science Teachers Association of Nigeria, Vol.34, No.1\&2, 43-66.

[8] Nworgu, B.G. (2010). Research in Science Education in Nigeria: Conceptual, Methodological and Analytical Issues. Guest Lecture Delivered at the 2nd National Conference of The School of Sciences, Federal College of Education, Okene, August 10-13.

[9] Osuafor, A.M. (1999). Extent of Use of Research Findings on Instructional Strategies in Science Education. Journal of Science Teachers Association of Nigeria, Vol.34, No.1\&2, 107112

[10] Sullivan, Peter and Mousley, Judith (1994). Quantity Mathematics Teaching: Describing Some Key Components. Mathematics Education Research Journal, Vol.6, No.1, 4-22. 